The final publication is available at Springer via:

http://dx.doi.org/10.1007/978-1-4939-0953-7

\title{
Chapter 10. Forest landscape ecology and global change: what are the next steps?
}

João C. Azevedo ${ }^{1 *}$, Maria Alice Pinto ${ }^{1}$, Ajith H. Perera ${ }^{2}$

${ }^{1}$ CIMO-Centro de Investigação de Montanha, Instituto Politécnico de Bragança,

Campus de Santa Apolónia, Apartado 1172, 5301-854 Bragança, Portugal

${ }^{2}$ Ontario Forest Research Institute, Ontario Ministry of Natural Resources, 1235 Queen

Street East, Sault Ste. Marie, Ontario, P6A 2E5, Canada

* Corresponding Author: Telephone (+351) 27-330-3341; Fax (+351) 27-332-5405; email: jazevedo@ipb.pt

1. The promising role of landscape ecology in dealing with change ......................... 2

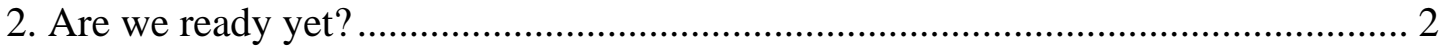



2.2. Are we prepared to deal with change in practice? ................................... 5

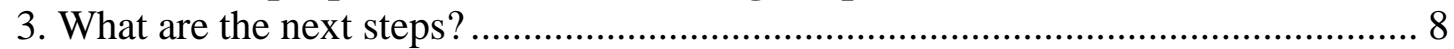

3.1. Emerging fields and new directions in research and management ........... 8



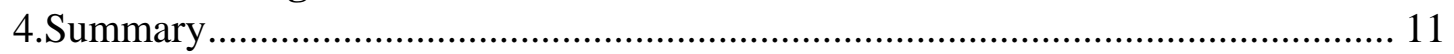

\section{Abstract}

In this chapter, we summarize current trends and challenges and future research directions in forest landscape ecology and in management related to global change. We discuss the available knowledge in forest landscape ecology and the possibilities of using this knowledge to support management under changing conditions. We also discuss the forest sector's preparedness to deal with changes in management and how forest landscape ecology can guide this management. Forest landscape ecology has gathered substantial knowledge on patterns, processes, tools, and methods that can support forest and landscape management during changing scenarios. We recognize that existing knowledge is incomplete and that a substantial portion of our knowledge is uncertain, that variability in landscape conditions and various forms of error compound the problem, that we still lack considerable knowledge in some fields, and that there are likely to be knowledge gaps we are not aware of. We nonetheless face the challenge of responding to change based on the available knowledge. 


\section{The promising role of landscape ecology in dealing with change}

As the authors of previous chapters have discussed, more than 30 years of forest landscape ecology research has led to the development of a body of essential knowledge, theory, research methods, and tools that have improved our understanding of forest landscapes and management of these landscapes. We know much more today than we knew even in the recent past about how forest landscapes are spatially structured, how their structure interacts with physical and biological processes, and how patterns and functions are affected by many drivers of change. In addition, we now have access to an extraordinary array of tools for collecting, analyzing, integrating, and drawing inferences from large spatial and temporal data sets. Both our existing knowledge and these new tools are improving our ability to plan and implement sound forest management practices and to prepare ourselves to face global changes. But are we ready yet?

\section{Are we ready yet?}

Population growth, climate change, land-use change, changes in management paradigms, and changes in management processes, among other proximate and ultimate drivers and processes of change, are creating increasing pressure on forest landscapes, which are already vulnerable or degraded in many parts of the world, thus creating additional stresses and threatening the provision of ecosystem services. Landscape ecology now has a much higher capability to inform management and decision-making in a context of change than ever before, and can play a decisive role in mitigating or reversing ongoing degradation processes, thereby permitting sustainable or more sustainable provision of ecosystem services.

In spite of the enormous advances in landscape ecology, this field of research is still developing and maturing rapidly (Wu 2013) and the challenges facing this field of study are many. Questions such as "how much do we really know about change and its effects on landscapes?” or “how prepared are we to deal with such change in practice?” are not just legitimate; on the contrary, they are essential to ask, and the answers will define the future direction of landscape ecology and how we evaluate the role of this field from the perspective of practical applications.

\subsection{How much do we really know?}

The question of what we know and how well we know it is not just an epistemological question, in the sense of how much we are theoretically able to know 
about any topic, but rather is a pragmatic question whose answer constrains our ability to deal with real-world landscape change situations based on existing knowledge. Forest landscape ecology has advanced in many fields, thereby improving both the availability and the certainty of knowledge (Fig. 10.1, top left), but there are recognized knowledge gaps (Fig. 10.1, top right). Climate change and its effects on populations, ecosystems, and landscapes provide an increasingly important example. The process of climate change is not fully understood in terms of its causes, the underlying mechanisms, and the likely outcomes. In addition, research on the ecological effects of climate change has not yet provided sufficient information on basic physiological, biological, and ecological attributes of species that would let us address the impacts of climate change on biological diversity. Iverson et al. (2014) discuss this in Chapter 2 of this book. Since research in this field relies heavily on modeling, the uncertainty of in the knowledge leads to high uncertainties in model predictions. Considering the large number of species and interactions in ecosystems and landscapes, gathering enough knowledge about these attributes seems difficult to accomplish within a reasonable timeframe, particularly considering that a large proportion of the known species are currently threatened and that many (perhaps most) existing species have not yet been identified. 


\section{Knowledge existence}

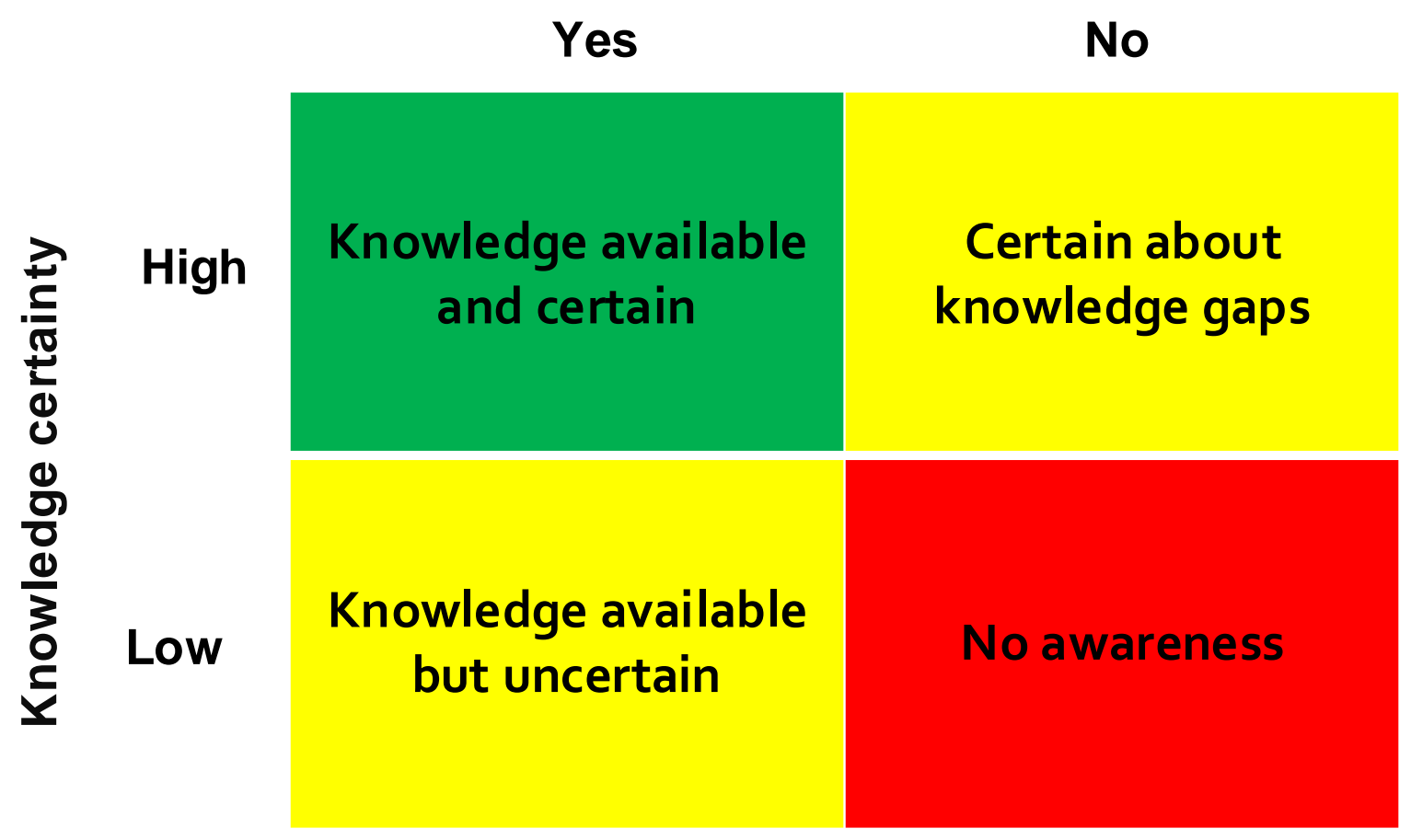

Figure 10.1. The balance between knowledge availability and certainty.

Land-use change provides another good example. The available models can predict many of the effects of such changes on landscape patterns and on some landscape processes, but knowledge gaps are known to exist. For example, we do not understand the known interactions between forest composition and forest structure sufficiently well to account for these interactions in our assessments of the effects of landscape change on wildfires. Rego and Silva (2014) discuss this in Chapter 3 of this book. More importantly, we lack a full understanding of the complex feedback loops among the drivers of change and their effects. Farinaci et al. (2014) discuss this in Chapter 4 of this book. Furthermore, the lack of knowledge of carbon distribution, temporal changes in this distribution, and the underlying regulatory mechanisms for many ecosystem components limits our understanding of carbon cycles. Chen et al. (2014) discuss this in Chapter 6 of this book.

On the other hand, existing knowledge is seldom certain. Low certainty results from the fact that our knowledge frequently derives from research conducted at a particular temporal or spatial scale that prevents us from transferring those results to other scales. The knowledge may instead derive from particular landscape and 
experimental conditions that cannot be replicated or that differ from those in other landscapes, or from the application of inappropriate analytical methods that produce misleading or uncertain conclusions. We are not sure, therefore, whether the knowledge gained from a particular setting will apply to a different one. In addition, the complexity and natural variability of land systems makes it very difficult to distinguish uncertainty in our knowledge from the uncertainty that is inherently associated with the behavior of complex systems. This may be more evident in modeling, where variability of the system and uncertainty of model predictions are intermixed. The level of certainty of current knowledge is therefore often low (Fig. 10.1, bottom left). The fact that landscape ecology has not been able to produce scientific theories or laws that offer universal predictive power, like in many other fields of ecology, may not arise solely from our philosophical perspectives on ecological systems; rather, it may be at least in part due to the complexity and variability of the systems that we study and the lack of sufficient knowledge about how to apply our knowledge at a broader level, to different systems and scales.

The most striking knowledge challenge, however, is that we don't yet know what questions we have not yet identified and tried to answer (Fig. 10.1, bottom right). As science progresses and our knowledge grows, revealing what was previously unknown simultaneously creates the need for more knowledge to answer questions we had not formerly known existed, thereby revealing new gaps that become target areas for new research. These gaps are not known until a field evolves sufficiently to reveal their existence; therefore, they cannot be predicted. Although we don't currently know how much we don't know, it is reasonable to predict that there is, and will continue to be, unknown knowledge that may be critical for some future application.

\subsection{Are we prepared to deal with change in practice?}

Our preparation to deal with change in practice relies only in part on existing knowledge in landscape ecology and related scientific fields. It is mostly a function of the perceptions and willingness of society, as a whole, and particularly the economic and decision-making agents, to recognize change and the need to act in order to prevent or mitigate its negative consequences. In addition, we may be missing opportunities to harness the incredible energy of natural processes as a tool for coping with change. To answer the question about our preparation, we must consider landscape ecology as a 
scientific field separately from forest management at landscape and other levels, in the context of social and economic needs.

\subsubsection{Forest landscape ecology}

Although Wu and Hobbs (2002) identified "causes, processes, and consequences of land use and land cover change" as the second-most-important research topic in their "top 10 list for landscape ecology in the 21st century”, no other change-related issues were identified by the landscape ecology community at the turn of the century as particularly relevant for the near future. The term "climate change" was used in only $3.7 \%$ of all papers published in all issues of the journal Landscape Ecology in 2002, although its frequency of use had increased in recent years (Wu 2013). However, the top 10 research topics in the last decade as identified by Wu (2013) includes several references to landscape change: land-use and land-cover change (ranked $5^{\text {th }}$ ), interactions between landscapes and climate change (ranked $7^{\text {th }}$ ), and ecosystem services in changing landscapes (ranked $8^{\text {th }}$ ).

Climate change has not been sufficiently addressed at the landscape level (Opdam et al. 2009), but change has been addressed frequently enough in the landscape ecology literature, whether directly or indirectly, through the analysis of change-related processes such as forest fragmentation or management, thereby providing relevant information that can be useful in an applied perspective under changing scenarios. Azevedo et al. (2014) discuss this in Chapter 1 of this book. Considerable limitations result from gaps in our knowledge and from areas of knowledge with low certainty, as noted earlier in this chapter, but knowledge gathered in recent decades can, at least in part, support management in terms of the design and implementation of prevention, adaptation, and restoration measures. Some of the syntheses presented in this book build a bridge between science and management to provide solutions that can be used in practical management to deal with change. See chapters 1 (Azevedo et al. 2014), 2 (Iverson et al. 2014), and 7 (Saura et al. 2014) of this book for details.

\subsubsection{Forest landscape management}

With the exception of climate change, all processes that are responsible for landscape change are driven by socioeconomic factors such as population growth or infrastructure development. Dealing with change in these cases mainly focuses on economics (both macro- and microeconomics), policy development, planning, and other fields that operate at scales above the landscape — often at global scales—and that focus 
on much more complex socioecological systems that combine aspects of human and natural systems.

The theoretical and technical foundations for management under ongoing and predicted change are available for the forest sector and other sectors that deal with forest landscapes in most parts of the world. However, there are clear limitations in our knowledge of forest management; for example, we currently lack sound silvicultural models that could be used to manage complex forests, particularly when it is necessary to meet multifunctionality requirements. Despite this, existing knowledge can support management of forest landscapes under changing conditions. For example, guidelines for forest management under climate change (e.g., Millar et al. 2007) are already available and have been applied in some parts of the world. Forest management philosophies have changed during the last decades of the $20^{\text {th }}$ century as a result of the introduction of systems analysis, consideration of multiple spatial and temporal scales, and dynamics concepts. By accounting for these new ideas, ecosystem management, sustainable forestry, and adaptive management are better suited to dealing with change and with its intrinsic uncertainty. See chapters 1 (Azevedo et al. 2014) and 9 (Coulson et al. 2014) of this book for more details. In addition, the computational, logistics, and other tools that are currently available can be applied in managing forests that are being affected by processes of change, whether that change is physical, socioeconomic, or both simultaneously.

\subsubsection{Barriers that arise from the interaction between science and society}

Synthesizing these observations about the science and social contexts of landscape ecology reveals that, at the management level, preparation for change relies strongly on organizational or institutional culture, policy (national and local, public and private), planning, and knowledge transfer. The real degree and extent of the implementation of forest landscape management approaches that currently account for change is not fully known, since available examples of management that have been reported are usually restricted to the public sector in few areas of the world, and even in these cases, the information is sparse. Accounting for change is limited to a few cases, most of which are government-driven and in developed countries. Climate change in particular, although seen by the public and now governments as a major driver of change and a threat in many ways, has not significantly affected how forests and other land-use categories are managed. At the corporate and business management levels, the 
extent of plans to adapt management processes in response to climate change and other sources of change is unknown, but is probably low.

At an institutional level, barriers exist that slow the incorporation of adaptation to change into management policies. This slowness results from several circumstances, including the following:

- Lack of awareness of change and its consequences.

- $\quad$ Lack of management principles and methods that account for change and its effects.

- Inertia, leading to an unwillingness to change how things are done in response to new challenges and processes.

- Insufficient conceptual and technical preparation of individuals to deal with change.

- Insufficient incentives from governments, markets, and others to account for change in planning.

- Minimal pressure from the public.

Some of these barriers are related to issues at a societal level, such as a lack of awareness and pressure from the public. Others are related to companies and government organizations that prevent or slow down the incorporation of change in their management activities. A particular group of barriers relates to insufficient development of an awareness of change, from scientific and management points of view, in academia, and, consequently, poor preparation of graduates to help institutions in areas that are being or will be affected by change, such as forestry.

\section{What are the next steps?}

From what we have discussed so far, limitations and barriers exist for both the sciences of landscape ecology and forest management and their practice at the landscape level. However, these obstacles also represent opportunities for landscape ecology and for society, and they are essential for helping us to define future directions for research and development.

\subsection{Emerging fields and new directions in research and management}

New fields within or related to landscape ecology that are under development will strongly benefit forest landscape ecology, particularly in terms of building up our knowledge and providing new tools to deal with change. 
One of the fastest growing fields is landscape genetics. This field involves studying the interactions among landscape composition, configuration, and matrix quality in terms of evolutionary processes such as gene flow, genetic drift, and selection (Manel et al. 2003, Storfer et al. 2007). Spatially explicit data and spatial analysis tools are used to detect genetic patterns and to test their relationships with landscape patterns. The importance of the discipline, in a context of change, is very high. Many of the genetic patterns that have been analyzed using a landscape genetics approach resulted from changes in the landscape's structure, such as land-use change, forest fragmentation, intensification of forestry practices, and climate change. Changes in landscape structure therefore affect the genetic diversity patterns of populations and, often, the risk of extinction of these populations. Given the relevance of biodiversity in forest landscapes (see Chapter 7 of this book [Saura et al. 2014] for more details), landscape genetics will become a powerful approach for analyzing the effects of change processes on biodiversity (Manel and Holderegger 2013). Similarly, landscape genetics can provide knowledge to support management and conservation measures at landscape and regional levels to help prevent or minimize extinctions and to contribute to sustainable forest management.

Another emerging field that has grown extraordinarily is the study of ecosystem services. The ecosystem services concept and related methodologies can contribute powerfully to providing forest landscape ecology with many conceptual and methodological tools to analyze landscape change in terms of its impact on society and, through an analysis of tradeoffs, to provide insights into how to optimize landscape structures and their management for the well-being of human communities. A great deal of ongoing research in landscape ecology relates to mapping the supply and demand for ecosystem services based on the landscape's composition, configuration, and processes. See chapters 1 (Azevedo et al. 2014), 5 (Marta-Pedroso et al. 2014), and 9 (Coulson et al. 2014) of this book for further discussion of this topic.

In addition to the ecosystem services approach, new directions in landscape ecology aim at the integration of socioeconomic factors in a broader landscape perspective. This is of utmost importance for the science of landscape ecology because change is often driven and carried out by the socioeconomic side of the human-nature system, because human societies are suffering from most of the consequences of change, and because solutions must be found on the socioeconomic side. Advances in multidisciplinary, interdisciplinary, and even transdisciplinary research are part of the 
required research agenda for the coming century to help us better integrate insights from the social and natural sciences within landscape ecology. This integration has been, at least in some parts of the world, a distinctive element of landscape ecology research. The promotion of interactions among scientists and with agents from fields outside the landscape ecology field of research, such as education, management, business, decisionmaking, and the public is, therefore, a priority.

The incorporation of change in management and planning at a broader (landscape) scale should be an essential goal of forestry in the $21^{\text {st }}$ century. Sustainable forestry has recently contributed to preventing or mitigating the negative effects of forest management on people, soils, water, wildlife, and the landscape, thereby preventing degradation of forest landscapes in response to a growing demand for forest products in many parts of the world. Forest management can also anticipate changes by investing in species, rotations, harvesting technologies, and other management options to improve the ability of forestry to adapt to new biophysical, business, and market conditions, for example, and by improving efficiency and increasing innovation in the forestry sector. These are necessary directions for forest landscape management. On the other hand, the design and management of landscapes that will be resilient against climate change (Opdam et al. 2009) is another important goal of forest management and planning at a landscape level, particularly in terms of the effects of management on disturbance regimes and biological invasions.

\subsection{Knowledge transfer}

One aspect of forest landscape ecology that appears to have been overlooked by researchers is the transfer of knowledge to land managers and policymakers who practice landscape management. Although knowledge has been advanced steadily, energetically, and systematically by researchers, a noticeable gap has formed between the developers of knowledge and those who could apply that knowledge. This is a result of differences in educational backgrounds, focal scales, goals, and institutional cultures between landscape ecology researchers and forest managers (Turner et al. 2002). This state was recognized and brought to the attention of forest landscape ecologists almost a decade ago, with the goal of creating awareness and encouraging attempts to bridge the knowledge gap (Perera et al. 2006). Unfortunately, the topic of knowledge transfer has not gained much traction among researchers, and remains a lower priority in formal discussion forums such as at scientific conferences and in publications. 
However, the focus on knowledge transfer is even more relevant now, and its importance is likely to increase. As we explore the challenges to forest landscape ecology applications in a changing world, knowledge transfer will play a primary role. If a gap had formed between knowledge developers and practitioners who are consumers of that knowledge in the past, during a time when the context was less dynamic and more simple, imagine how this gap has widened in the present context of dynamic and complex changes, as has been discussed in the previous chapters of this book.

Here, we want to stress that forest landscape ecology researchers must actively engage in knowledge transfer, instead of passively expecting practitioners to seek out our knowledge. Many opportunities exist for us to do so. For example, we can aim to engage practitioners in a two-way dialogue from the outset of our research and to establish an ongoing feedback loop through practices such as adaptive management. We could reduce the time lag between detecting problems that affect practitioners and developing solutions through research by resorting to iterative options such as simulation modeling of scenarios. Fortunately, the task of transferring knowledge has become easier due to improved infrastructures: technological tools such as spatially explicit databases and analytical software and hardware, as well as skilled personnel who can use these tools, are now readily available to forest landscape managers.

There is another advantage of a dialogue between researchers and practitioners such as forest landscape managers: the benefit that researchers derive from the wisdom and experience of practitioners. This wealth of "expert knowledge”, which is typically latent, can be now elicited and formulated quantitatively using advanced statistical techniques (Perera et al. 2012). Incorporating knowledge transfer as an essential component in forest landscape ecology research projects has an extra incentive: researchers are increasingly encouraged, and sometimes even required, to demonstrate the applications of their proposed research both to advance science and to advance the application of that science.

\section{Summary}

Forest landscape ecology has gone through a period of rapid development since the 1980s, leading to the development of a sub-field of landscape ecology that deals with patterns, processes, and changes in forest landscapes and their close connection to forest management. Change has been part of landscape ecology from the beginning of 
the discipline, but its importance has recently grown due to increasing perception of new change processes, increasing and accelerating effects of processes that were already known, and interactions among different drivers and change processes, accompanied by a growing recognition of the state of degradation or vulnerability of forest landscapes around the world.

In this book, we have attempted to produce a synthesis of the most relevant topics within the study of changes in forest landscapes to provide readers with state-of-the-art information and to provide insights into how to apply the existing knowledge to prevent or mitigate problems related to change and to understand the limitations and challenges to the study of forest landscape change. Climate change is one of the relatively newly perceived drivers that is already affecting forest landscapes. However, its short- and long-term impacts on forest stands, on the landscape's composition, and on ecological processes are not yet fully understood, although we know they can significantly affect the distribution and functioning of these systems. Iverson et al. (2014) discuss this in Chapter 2 of this book. This and other drivers of change at stand and landscape scales are greatly affecting key processes, such as fire regimes, and are consequently affecting forest landscapes in most parts of the world. Rego and Silva (2014) discuss this in Chapter 3 of this book. Socioeconomic drivers of change are dominant factors around the world, and operate at different scales and directions in different parts of the world. They are also affected by different drivers, such as climate change. Farinaci et al. (2014) discuss this in Chapter 4 of this book. Biodiversity, even more than other ecosystem and landscape components, has been affected by forest landscape changes of many different types and origins, and potentially in irreversible ways in some parts of the world. Changes in the amount, quality, fragmentation, connectivity, and heterogeneity of forest habitats directly affect the forest ecosystem's ability to support populations, and have significant implications for ecosystem resilience and the provision of a large array of ecosystem services. Saura et al. (2014) discuss this in Chapter 7 of this book.

Past, current, and future landscape changes can be described, analyzed, assessed, monitored, and modeled in diverse ways. The development of a relevant theoretical framework and set of methods for studying change is an important legacy of landscape ecology. Gómez-Sanz et al. (2014) discuss this in Chapter 8 of this book. A novel approach to evaluate change simultaneously from biophysical and socioeconomic perspectives is based on the ecosystem services concept. This has proven to have enormous potential for scientific use, but also for decision-making in complex 
socioeconomic and ecological systems, where economic considerations may be dominant. Marta-Pedroso et al. (2014) discuss this in Chapter 5 of this book. Among other services, carbon sequestration by forest landscapes is now widely recognized both by society and by the business community. The large amounts of carbon stored in forests and the vulnerability of this storage to forest management, as well as the complex dynamics that occur in forest systems and their effects on carbon cycling, make this a key issue in forest landscape ecology and other scientific fields. Chen et al. (2014) discuss this in Chapter 6 of this book.

The development of the topics discussed in this chapter and throughout this book provide valuable knowledge of potential applications of this knowledge in real-world management scenarios related to biodiversity conservation, carbon sequestration, fire management, evaluation of ecosystem services, and landscape monitoring. New directions in landscape ecology that are currently under development, such as landscape genetics and ecosystem services, can benefit forest landscape ecology by providing additional knowledge and tools to help us deal with change.

The available knowledge in forest landscape ecology related to change is possibly sufficient to support management under changing conditions, although identified and unidentified knowledge gaps exist. The preparedness of the forest sector to deal with change is currently insufficient. The incorporation of adaptation to change in business and forest management and planning should become a priority, and knowledge transfer is an essential but under-used element in developing strategies to help organizations learn to deal with change.

\section{References}

Azevedo JC, Pinto MA, Perera AH (2014) Chapter 1. Forest landscape ecology and global change: an introduction. In: Azevedo JC, Perera AH, Pinto MA (eds) Forest landscapes and global change: challenges for research and management. Springer, New York, pp 1-27.

Chen JQ, John R, Sun G, McNulty S, Noormets A, Xiao JF, Turner MG, Franklin JF (2014) Chapter 6. Carbon fluxes and storage in forests and landscapes. In: Azevedo JC, Perera AH, Pinto MA (eds) Forest landscapes and global change: challenges for research and management. Springer, New York, pp 139-166.

Coulson RN, Birt A, Tchakerian MD (2014) Chapter 9. Forest landscape management in response to change: the practicality. In: Azevedo JC, Perera AH, Pinto MA 
(eds) Forest landscapes and global change: challenges for research and management. Springer, New York, pp 227-248.

Farinaci JS, Ruseva TB, Tucker CM, Evans TP, Batistella M (2014) Chapter 4. Humans as agents of change in forest landscapes. In: Azevedo JC, Perera AH, Pinto MA (eds) Forest landscapes and global change: challenges for research and management. Springer, New York, pp 75-105.

Gómez-Sanz V, Bunce RGH, Elena-Rosselló R (2014) Chapter 8. Landscape assessment and monitoring. In: Azevedo JC, Perera AH, Pinto MA (eds) Forest landscapes and global change: challenges for research and management. Springer, New York, pp 199-226.

Iverson LR, Prasad AM, Matthews SN, Peters MP (2014) Chapter 2. Climate as an agent of change in forest landscapes. In: Azevedo JC, Perera AH, Pinto MA (eds) Forest landscapes and global change: challenges for research and management. Springer, New York, pp 29-49.

Manel S, Holderegger R (2013) Ten years of landscape genetics. Trends Ecol Evol 28:614-621.

Manel S, Schwartz MK, Luikart G, Taberlet P (2003) Landscape genetics: combining landscape ecology and population genetics. Trends Ecol Evol 18:189-197.

Marta-Pedroso C, Laporta L, Proença V, Azevedo JC, Domingos T (2014) Chapter 5. Changes in the ecosystem services provided by forests and their economic valuation—a review. In: Azevedo JC, Perera AH, Pinto MA (eds) Forest landscapes and global change: challenges for research and management. Springer, New York, pp 107-137.

Millar CI, Stephenson NL, Stephens SL (2007) Climate change and forests of the future: managing in the face of uncertainty. Ecol Appl 17:2145-2151.

Opdam P, Luque S, Jones K (2009) Changing landscapes to accommodate for climate change impacts: a call for landscape ecology. Landsc Ecol 24:715-721.

Perera AH, Buse L., Crow TR (2006) Knowledge transfer in forest landscape ecology: a primer. In: Perera AH, Buse L, Crow T (eds) Forest landscape ecology: transferring knowledge to practice. Springer, New York, pp 1-18.

Perera AH, Drew CA, Johnson CJ (2012). Expert knowledge and its applications in landscape ecology. Springer, New York.

Rego FC, Silva JS (2014) Chapter 3. Wildfires and landscape dynamics in Portugal—a regional assessment and global implications. In: Azevedo JC, Perera AH, Pinto 
MA (eds) Forest landscapes and global change: challenges for research and management. Springer, New York, pp 51-73.

Saura S, Martín-Queller E, Hunter ML Jr (2014) Chapter 7. Forest landscape change and biodiversity conservation. In: Azevedo JC, Perera AH, Pinto MA (eds) Forest landscapes and global change: challenges for research and management. Springer, New York, pp 167-197.

Storfer A, Murphy MA, Evans JS, Goldberg CS, Robinson S, Spear SF, Dezzani R, Delmelle E, Vierling L, Waits LP (2007) Putting the landscape in landscape genetics. Heredity 98:128-142.

Turner MG, Crow TR, Liu J, Rabe D, Rabeni CF, Soranno PA, Taylor WW, Vogt KA, Wiens JA (2002) Bridging the gap between landscape ecology and natural resource management. In: Liu J, Taylor WW (eds) Integrating landscape ecology into natural resource management. Cambridge University Press, Cambridge, pp 433-465.

Wu J (2013) Key concepts and research topics in landscape ecology revisited: 30 years after the Allerton Park workshop. Landsc Ecol 28:1-11.

Wu JG, Hobbs R (2002) Key issues and research priorities in landscape ecology: an idiosyncratic synthesis. Landsc Ecol 17:355-365. 